\section{Improving the expressive \\ language skills of teenagers with Down's syndrome}

\section{Sue Buckley}

\author{
Sarah Duffen Centre \\ Department of Psychology \\ University of Portsmouth \\ U.K.
}

\begin{abstract}
This article reports on the effectiveness of an intervention programme designed to improve the morpho-syntax used by teenagers with Down's syndrome in their speech. The intervention used reading to teach the language. All but one of the teenagers were using longer, more complex sentences, in their conversation at the end of the year's training. The extent of individual progress was significantly related to speech production ability and comprehension of grammar at the end of the year. Future language intervention programmes should focus on both phonology and grammar.
\end{abstract}

(C) 1993, 1999. The Down Syndrome Educational Trust Down Syndrome Research and Practice 1995, 3 (3) 110-115

\section{Introduction}

\section{The language profile}

The typical speech and language difficulties of the current generation of adolescents and adults with Down's syndrome have been fairly well documented, with agreement among authors regarding the usual profile of communication difficulties and their relationship to non-verbal cognitive abilities.

Firstly, a number of studies have demonstrated that the language skills of children and adults are more impaired than would be expected relative to measures of their cognitive development indexed by general intelligence tests or by measures of non-verbal abilities. (For reviews see Fowler, 1990; Chapman, 1995; Rondal, 1994.)

Secondly, studies have identified that within the language domain, the development of the lexicon (vocabulary) is less delayed than the development of morpho-syntax (grammar), that production of morpho-syntax is more delayed than comprehension, that pragmatics (skill in using language to communicate) is relatively good and that phonology (speech - motor production), and therefore speech intelligibility, is relatively poor (Rosin, Swift, Bless and Vetter, 1988; Chapman, 1994; Fowler, 1995; Bray and Woolnough, 1988).

Thirdly, the actual level of expressive language skills attained by adolescents with Down's syndrome rarely exceeds that of the typically developing three to five year old (Fowler, Gelman and Gleitman,1994).

\section{Possible reasons}

The majority of studies to date are mainly descriptive, although some authors do discuss the possible reasons for this profile of difficulties. A number of suggestions have been put forward, including hearing impairment (since about 40\% of people with Down's syndrome have mild hearing loss; 10$15 \%$ more severe hearing loss), particular difficulty with verbal processing, difficulties with rule learning (since learning the language structure is more difficult than learning vocabulary), a shut-down in development or critical period (as originally suggested by Lenneberg, Nichols and Rosenberg, 1964) and the influence of poor phonology. These are summarised and evaluated by Fowler, Gelman and Gleitman (1994). Others have also suggested a pervasive processing deficit (Rosin, Swift, Bless and Vetter, 1988) and poor auditory short-term memory skills (Kay-Raining Bird and Chapman, 1994).

\section{Lack of intervention}

To the author's knowledge, there have been no intervention studies conducted, to see if it is possible to improve the speech and language of teenagers. This is the aim of the present study, which was designed to answer the following questions:

1.Can intervention improve the grammatical competence of teenagers with Down's syndrome?

2. Will teaching using reading activities be more effective than speech practice alone?

3. Will teaching improve the comprehension and production of grammar equally?

4.Can intervention close the gaps between non-verbal mental ability and language abilities, and between lexical and syntactic abilitios? 
5. Will there be significant individual differences and, if so, why?

\section{The study}

12 students with Down's syndrome, 6 boys and 6 girls, were recruited to the intervention study from three local special schools. Their ages ranged from 13 years 4 months to 15 years 11 months ( group mean 14 years 10 months) at the start of the intervention year. They all took part in an intervention programme which continued throughout an academic year (for 9 months).

\section{The intervention programme}

The first part of the intervention programme involved the students in intensive practice of new sentence structures. Using a controlled experimental design, the effectiveness of two teaching methods, speech only (S) and speech and reading (SR) were compared across a number different grammatical and syntactical structures. The sentence structures chosen for teaching were selected from those that can be assessed using the Test for Reception of Grammar (Bishop, 1983).

Picture materials were prepared to illustrate twelve different examples of each of the six structures taught. In both training conditions, the investigator pointed at the picture and spoke the sentence for the student to repeat. In the speech and reading method, the sentence was written under the picture, in the speech only method the cards contained the pictures only. This part of the intervention and the results have already been reported (Buckley, 1993). Overall, the reading and speech method was more effective than the speech only method, but there were considerable individual differences in the size of the gains. During this experimental part of the study, all the students' speech practice on the training trials was recorded on audio-tape with the student holding a microphone to speak in to. They enjoyed doing this and were able to listen to themselves and to the model sentences provided by the instructor.

At the end of this period of experimental training of each structure, the sentence structures were used to talk and write about everyday activities and experiences in a variety of ways. Written support was used for all these generalisation activities as the first part of the study had illustrated that some of the teenagers found learning from listening only very difficult indeed (see Buckley, 1993).

The students made picture books, using a Polaroid camera to record themselves acting out sentence meanings. For example:

For comparatives the students found a school friend who was taller than themselves and another who was shorter and they were photographed with each so that the sentences:

Claire is shorter than Paul

Paul is taller than Claire

Claire is taller than Jenny

Jenny is shorter than Claire

could be illustrated and then read and practised.

For passives, the teenagers were photographed gently pushing each other to illustrate:
Claire is pushing Jenny

Jenny is being pushed by Claire

Jenny is pushing Claire

Claire is being pushed by Jenny

For the prepositions above and below, the teenagers sat on or under a large table to illustrate:

Paul is above Claire

Claire is below Paul

Claire is above Paul

Paul is below Claire.

The teenagers thoroughly enjoyed acting out the sentences and waiting for the Polaroid prints to develop, usually keeping them warm in their jumpers! Then they pasted them into their own language books and wrote in the sentences. Some could copy-write, others needed more help. Only seven of the twelve could read well enough to score on the Neale Analysis of Reading Abilities (Neale, 1966) at the beginning of the year. In addition to these books, the students had worksheets prepared with pictures and sentence examples. The easiest sheets simply required the student to copy the sentence and to practise reading it with whatever help was needed. As they progressed, the worksheets had words missing from the sentences and they were asked to complete them with the correct words.

These books and worksheets were taken home and parents were asked to help the students to practise at home. Daily conversation diaries were also made, containing a sentence about an activity or experience at home or at school, which the student wanted to record. These diaries also went between home and school with parents, teachers and students all contributing items for the diaries. The rule was that the diary entry must be written in dialogue form, so giving the student a model for talking about their daily lives in complete, grammatically correct sentences.

\section{Outcome measures}

At the beginning and the end of the intervention year measures were taken of the students' language skills and cognitive abilities.

Vocabulary comprehension was measured using the British Picture Vocabulary Scale (BPVS) (Dunn, Dunn, Whetton and Pentilie, 1982) and comprehension of grammar using the Test for Reception of Grammar (TROG) (Bishop, 1983). Language production was measured using conversation samples and imitated production.

Twelve minute conversation samples were recorded with the instructor talking with each student about current, past and future activities, favourite TV programmes, holidays and families. The conversations were transcribed by two independent transcribers, who then reached a consensus over any discrepancies in transcription by listening to tapes again. Number of utterances collected in twelve minutes ranged from 57 - 130, mean 83 - depending on the fluency of the young person. Mean Length of Utterance (MLU) in morphemes (Brown, 1973), was used as a standard measure of grammatical complexity and MLU scores were converted to age equivalent scores using the regression equation (Mental Age $=.64[\mathrm{MLU}]+1.75$ ) derived from preschool data by Chapman, Ross and Seung (1993). Imitated production was measured by recording the student's per- 
formance when imitating the TROG test sentences and scoring the percentage of words correctly produced for each sentence structure.

Non-verbal cognitive ability was measured using the Raven's Coloured Progressive Matrices (Raven, 1962) and the Digit Span test from the WISC was used to measure auditory and visual short-term memory. Visual span was measured using the digits written on cards presented at the standard rate. At the end of the summer term (Year 1), fifteen months before the start of the intervention year in the autumn term (Year 2), the students had been assessed on the BPVS and the TROG to enable a developmental baseline to be established for the language progress to be expected without intensive intervention. Intelligibility was rated subjectively on a scale of 1 (good) to 5 (poor) by the two independent raters who transcribed the tapes.

\section{Results}

\section{Effect of Intervention}

The figures in Table 1 illustrate the mean gains for the whole group on the standardised measures of language comprehension, language production and non-verbal cognitive ability during the intervention year, compared where possible with the baseline no-intervention year. year.

The gain of 4 months on the Matrices, and of 3 and 4 months on the language measures in the pre-training period suggest that this annual rate of growth might be typical for cognitive skills at this time in the young people's development (in the absence of targeted intervention).

The gain of 8 months in expressive syntax is significant $(p=$ .01) (All significant statistics - Wilcoxon Matched Pairs Signed Ranks Test), but unfortunately no baseline measure was taken in Year 1 for comparison. However, the data from two longitudinal studies suggests that growth in MLU is not to be expected at this time (Chapman, 1994; Fowler, 1988).

\section{Language Profile}

The standardised measures presented in Table 1, confirm the profile described in the introduction, with all language measures significantly delayed relative to non-verbal mental ability as indexed by the Raven's Coloured Progressive Matrices. Taking Year 2 pre-intervention measures within the language domain as typical, vocabulary comprehension is the least delayed and expressive language the most delayed. The difference between the BPVS and TROG scores is not statistically significant, but the MLU score is significantly different from both the language comprehension measures. (BPVS/MLU $p=.01)(T R O G / M L U p=.003)$.

Table 1. Cognitive and language profiles - pre and post intervention. Age equivalent scores.

\begin{tabular}{|c|c|c|c|c|c|}
\hline Year & CA & BPVS & TROG & Matrices & MLU \\
\hline 1 & $13 y 8 m$ & $5 y 3 m$ & $4 y ~ 8 m$ & - & - \\
\hline 2 & $14 y 11 \mathrm{~m}$ & $5 y 6 m$ & $5 y 0 m$ & $7 y 0 m$ & $3 y ~ 7 m$ \\
\hline 3 & $15 y 8 m$ & $5 y 11 m$ & $6 y 3 m$ & $7 y 4 m$ & $4 y 3 m$ \\
\hline Gain 1-2 & $15 \mathrm{~m}$ & $3 \mathrm{~m}$ & $4 \mathrm{~m}$ & - & - \\
\hline Gain 2-3 & $9 \mathrm{~m}$ & $5 \mathrm{~m}$ & $15 \mathrm{~m}^{* *}$ & $4 \mathrm{~m}$ & $8 \mathrm{~m}^{* *}$ \\
\hline
\end{tabular}

(** $p<.01$ Wilcoxon)

It can be seen that during the baseline 15 months, the students gained a mean of 3 months growth for vocabulary comprehension and 4 months for grammar comprehension. During the 9 month training period, mean vocabulary growth was 5 months while the students made mean progress of 15 months on grammar comprehension. This difference between progress with grammar over the baseline and intervention periods suggests that the targeted teaching of grammar was having a significant effect. There was no specific programme to teach new vocabulary during the year and the progress made here is similar to the gain of the previous
Table 2 illustrates the scores and the range in MLU and Table 3 gives the age equivalents of these ranges.

It is clear that there are a wide range of individual differences. These are not accounted for by age as there are no significant correlations with age for any of the measures.

The young people ranged in age from 13 years 4 months to 15 years 11 months at the start of the intervention year, a spread of 2 years 7 months.

Table 2. Mean Length of Utterance - conversation samples, pre and post intervention.

\begin{tabular}{|l|c|c|c|c|}
\hline & \multicolumn{2}{|c|}{ Year 2 MLU } & \multicolumn{2}{c|}{ Year 3 MLU } \\
\hline & Mean & Range & Mean & Range \\
\hline Girls & 2.90 & $1.08-6.26$ & 4.23 & $1.89-8.81$ \\
\hline Boys & 2.83 & $2.09-4.55$ & 3.41 & $2.76-4.55$ \\
\hline All & 2.86 & $1.08-6.26$ & 3.82 & $1.89-8.81$ \\
\hline
\end{tabular}

Table 3. Individual differences in MLU mental ages.

\begin{tabular}{|l|c|c|}
\hline Range & Year 2 & Year 3 \\
\hline Girls & 2y $5 \mathrm{~m}-5 \mathrm{y} 9 \mathrm{~m}$ & $3 \mathrm{y}-7 \mathrm{y} 5 \mathrm{~m}$ \\
\hline Boys & 3y $1 \mathrm{~m}-4 \mathrm{y} 8 \mathrm{mh}$ & 3y $6 \mathrm{~m}-4 \mathrm{y} 8 \mathrm{~m}$ \\
\hline All & 2y $5 \mathrm{~m}-5 \mathrm{y} 9 \mathrm{~m}$ & $3 \mathrm{y}-7 \mathrm{y} 5 \mathrm{~m}$ \\
\hline
\end{tabular}


The expressive language age based on MLU ranged from 2 years 5 months to 5 years 9 months, a spread of 3 years 4 months.

There are also no gender differences on any of the measures.

Other measured variables that might be predicted to have an effect on individual progress during the training year are language comprehension (BPVS, TROG), non-verbal mental age (Matrices), auditory and visual short term memory skills (digit spans), expressive skill at the start of the year (MLU) and speech production skills (intelligibility). Only two of these measures correlate significantly with the MLU gain during the training year, Intelligibility and TROG scores.

Intelligibility ratings ranged from 1 (good) to 5 (poor), group mean $=2.9$. Intelligibility was significantly negatively correlated with MLU ( $r=-.67, p=.01)$, (Spearman's rho is used for all correlations reported); the poorer the student's speech production skills, the smaller the gain in MLU.

The TROG score for comprehension of grammar was significantly positively correlated with MLU $(r=.58, p=.05)$. The better the student's level of comprehension for grammar at the start of the year, the greater their improvement in expressive production.

\section{Grammatical analysis}

A more detailed grammatical analysis of the conversations was undertaken in addition to the MLU scoring to see if there were significant gains in the conversational use of the parts of speech specifically targeted during the experimental phase of the training using the TROG sentences. These were articles (a, the), auxiliary verbs (is, are) personal pronouns, plurals, verb tense (-ing) and prepositions. The sentence structures also taught were comparatives, passives, ' $X$ not $Y$ ' and 'post modified subjects' (PMS).

There was no evidence for the use of comparatives, $\mathrm{X}$ not $\mathrm{Y}$, passives or PMS sentences in the final conversational samples though there was some improvement in correct imitated production of these sentences and the comprehension of them (see Buckley, 1993).

However, there were significant gains in the total number of articles $(p=.003)$, auxiliaries $(p=.006)$, -ing $(p=.003)$, plurals $(p=.001)$, prepositions $(p=.003)$ and pronouns $(p$ $=.002$ ). For pronouns and prepositions, both the frequency of occurrence and the number of different examples of the category used in the final conversation increased significantly.

There were also significant increases in the use of the irregular past tense $(p=.008)$ and the regular past $(-e d)(p$ $=.008)$.

If the total conversational vocabulary was divided into two categories, content versus function words, there was a significant increase in the number of different function words used in the last conversation $(p=.003)$. There was a $36.6 \%$ increase (164 to 224 different function words used by all teenagers). This mean number of new function words in the final conversation was 18.7 per student (range 7 - 35).

For the content words, there was a significant increase in number of bound morphemes used in the last conversation $(p=.002)$. The only bound morpheme (in the range used by the teenagers) which showed no significant increase was the possessive 's.

\section{Possible predictors of grammar gains}

When the measures of the teenagers' language and cognitive skills were considered in relation to the specific grammatical gains, there were some interesting patterns.

Vocabulary comprehension level (BPVS) at the start of the intervention year was significantly correlated with the increase in number $(r=.70, p=.011)$ and frequency of occurrence $(r=.61, p=.037)$ of pronouns and the frequency of occurence of prepositions $(r=.61, p=.032)$.

Grammar comprehension levels (TROG) at the start of the intervention year was significantly correlated with the gain in frequency of pronoun $(r=.59, p=.043)$ and plural $(r=$ $.57, p=.048)$ use only.

MLU at the start of the year was significantly correlated with increase in frequency of pronoun use $(r=.59, p=.042)$ only. Intelligibility was significantly negatively correlated with the increase in use of auxiliaries $(r=-.53, p=.07)$, -ed $(r=-.57$, $p=.054)$ possessive 's $(r=-.65, p=.02)$ prepositions $(r=$ $-.68, p=.016)$ and pronouns $(r=-.61, p=.03)$.

There were no significant correlations between the nonverbal mental age scores (Matrices) or the visual short term memory scores at the start of the year and any of the language outcome measures.

However, there were significant correlations between the auditory short term memory scores at the start of the year and the gains in frequency of use of possessive 's $(r=.62, p=$ .03) prepositions $(r=.65, p=.015)$ and the correction with irregular past tenses approached significance $(r=.56, p=$ $.06)$.

\section{Discussion}

While numerous papers have reported that the speech of people with Down's syndrome is usually restricted to 'telegraphic' utterances, with little development of morphosyntax, few suggest that intervention might be effective. This may reflect the view that environmental input has little effect on acquisition of grammar in children (Chomsky, 1965, 1968), although recent models such as the Child Talk model (Chapman, Streim, Crais, Salmon, Strand and Negri, 1992) challenge this assumption.

To the author's knowledge the study reported here is the first controlled and evaluated attempt to teach morpho-syntax, and the results are encouraging.

\section{Uneven language and cognitive profiles}

The profile of relationships between non-verbal cognitive ability and language measures before intervention is similar to that reported elsewhere (though non-verbal mental age measures may vary from study to study depending on the measures used). All the language measures lag behind non-verbal cognitive ability, with the acquisition of language structure rules (grammar) more delayed than the acquisition of a lexicon (vocabulary) and the ability to use expressive syntax lagging significantly behind both comprehension measures. 


\section{Effect of training}

The MLU range for the teenagers before intervention is comparable with that reported in other studies suggesting they are a typical group. For example Chapman, Schwartz and Kay-Raining Bird (1992) reported a mean MLU (based on a conversation sample) of 2.3 for 12 adolescents (age range 12 years 8 months to 16 years 0 months) and a mean MLU of 3.4 for 13 young people aged 16 years 5 months to 20 years 3 months. Rosin, Swift and Blesser (1988) report a mean conversational MLU of 2.88 for a group of ten boys with Down's syndrome, age range 10 years 6 months to 17 years 5 months.

In their longitudinal study Chapman, Ross and Seung (1993) report no MLU gain for the oldest group over a four year period. This is similar to the findings of Fowler (1988) who reports a plateau in MLU growth from 8 years - 13 years based on a longitudinal study of ten children with Down's syndrome.

It would seem that without intervention, little progress in MLU would have been expected for the teenagers in this study, whereas 11 of the 12 showed gains ranging from $0.27-2.66$, mean 0.96 .

The results of this study suggest that training which specifically targets grammar can produce significant gains in both comprehension and production.

Unfortunately, longitudinal follow up was not possible, so evidence of maintenance of the gains is needed. The gains in use of the function words that had been practised supports the view that the training was having a specific effect.

\section{The importance of phonology}

The significant correlation between the gain in MLU during intervention and the intelligibility rating, suggest that Fowler (1995) is right to draw attention to the possible role of the speech- motor difficulties experienced by most children with Down's syndrome, in delaying the acquisition of grammar.

That intelligibility was significantly negatively correlated with the gains in the use of the bound morphemes (-ed, possessive 's) is perhaps less surprising than its significant link with increased use of auxiliaries, prepositions and pronouns.

However, if a child is experiencing real difficulty in speaking clearly, the strategy of confining output to the key information carrying words is a good one if it enables greater intelligibility of the words used, as suggested by Bray and Woolnough (1988).

One intervention study which focused on improving phonology has reported gains in grammar (e.g. Cholmain, 1994) as a consequence. This result is consistent with the view that there are dynamic trade-offs between complexity of word combinations and phonetic complexity of lexical items in a limited capacity production system (Nelson and Bauer, 1991; Crystal, 1987).

\section{Comprehension and production}

The significance of the correlation of MLU gain with the TROG scores is not surprising, since it is presumably easier to learn to say words and structures that are already comprehended.
What is more surprising is the lack of significant correlation of most of the gains with vocabulary comprehension. The BPVS score only correlated significantly with increased use of pronouns and prepositions, suggesting they may be treated more like lexical items than other aspects of grammar.

\section{Auditory short term memory}

Auditory short term memory scores were significantly correlated with the increase in use of possessions, prepositions and irregular past tenses only.

The lack of auditory memory links with other outcomes may not be taken to mean it is not usually a significant factor in the language difficulties of these children.

The training method used visual prompts for language throughout, reducing the memory load on language processing and allowing a visual memory to support auditory memory for the language.

The auditory digit span score at the start of the year was significantly correlated to MLU at that point $(r=.62, p=.03)$.

\section{Conclusions}

This study should be seen as encouraging but preliminary. There is an urgent need for speech and language interventions for people with Down's syndrome to be evaluated. Too much of the literature seems to suggest that the usual difficulties are an inevitable consequence of the syndrome, particularly the poor grammar, yet there is no justification for this view until intensive interventions have been thoroughly investigated and evaluated.

It is likely that the profile is the result of complex interactions between the effects of hearing loss, speech-motor difficulties, auditory short term memory, speech processing difficulties and opportunities to practice.

Future language intervention programmes should focus on both phonology and grammar.

\section{References}

Bishop,D.V.M. (1983). TestforReception of Grammar(TROG). Manchester: Chapel Press.

Bray,M. and Woolnough,L. (1988) The language skills of children with Down's syndrome aged 12 to 16 years. Child Language Teaching and Therapy. 4, 311-324.

Brown,R. (1973). A First Language. London: Allen and Unwin.

Buckley,S.J. (1993). Developing the speech and language skills of teenagers with Down's syndrome. Down's Syndrome: Research and Practice. 1 (2) 63-71.

Buckley,S.J. and Sacks,B. (1987). The Adolescent with Down's Syndrome: Life for the Teenager and for the Family. Portsmouth Polytechnic.

Chapman,R.S. (1994). Language Development in Older Children and Adolescents with Down's Syndrome. Paper presented at the International Conference on Language and Cognitive Development in Children and Adults with Down's Syndrome, Sarah Duffen Centre, University of Portsmouth, UK September 1994.

Chapman,R. (1995). Language development in children and adolescents with Down syndrome. In P. Fletcher and B. 
MacWhinney (Eds), The Handbook of Child Language. Oxford: Blackwell.

Chapman,R.S., Ross,D.R. and Seung,H. (1993). Longitudinal language development in children and adolescents with Down syndrome. Paper presented at the American Speech-Language Association, University of WisconsinMadison, Wisconsin USA, November 1993.

Chapman,R., Schwartz,S.E. and Kay-Raining Bird,E. (1992). Language production of older children with Down syndrome. Paper presented at the 9th World Congress of the International Association for the Scientific Study of Mental Dificiency. Queensland, Australia August 1992.

Chapman,R.S., Streim,N., Crais,E., Salmon,D., Strand,E. and Negri,N. (1992). Child talk: assumptions of a developmental process model for early language learning. In R.S Chapman (Ed.), Processes in Language Acquisition and Disorders, 3-19. St Louis: Mosby-Year Book.

Cholmain,C.N. (1994). Working on phonology with young children with Down's syndrome: A pilot study. Journal of Clinical Speech and Language Studies, 1, 14-35.

Chomsky,N. (1965). Aspects of a Theory of Syntax. Cambridge, MA: MIT Press.

Chomsky,N. (1968). Language and Mind. New York: Harcourt Brace.

Crystal,D. (1987). Towards a bucket theory of language disability: taking account of interactions between linguistic levels. Clinical Linguistics and Phonetics, 1, 7-22.

Dunn, L.M., Dunn, L.M.L., Whetton,C. and Pentilie,D. (1982). British Picture Vocabulary Scale (short form). NFER-Nelson. Fowler,A. (1988). Determinants of rate of language growth in children with Down syndrome. In L. Nadel (Ed.) The Psychobiology of Down Syndrome. Cambridge: Bradford MIT.

Fowler,A. (1990) Language abilities in children with Down syndrome: evidence for specific syntactic delay. In D. Cicchetti and M. Beeghly (Eds.) Children with Down Syndrome. Cambridge: Cambridge University Press.

Fowler,A. (1995). Linguistic Variability in Persons with Down Syndrome. In L. Nadel and D. Rosenthal (Eds.) Down Syndrome: Living and Learning in the Community. New York: Wiley.
Fowler,A., Gelman,R. and Gleitman,L., (1994). The course of language learning in children with Down syndrome. In $\mathrm{H}$. Tager-Flusberg (Ed.) Constraints on Language Acquisition: Studies of Atypical Children. Hillsdale, NJ: Lawrence Erlbaum Associates.

Hamilton,C. (1993). Investigation of the articulatory patterns of young adults with Down's syndrome using electropalatography.Down's Syndrome: Research and Practice. 1 (1) 15-28.

Kay-Raining Bird,E. and Chapman,R.S. (1994). Sequential recall in individuals with Down's syndrome.Journal of Speech and Hearing Research. 37, 1369-1380.

Lenneberg,E.H., Nichols,I.A. and Rosenberg,E.F. (1964). Primitive stages of language development in mongolism. Research Publication, Association for Research in Nervous and Mental Disease. 42, 119-147.

Neale,M.D. (1966). Neale Analysis of Reading Ability, 2ndEd. London: Macmillan Education.

Nelson,L.K. and Bauer,H.R. (1991). Speech and language production at age 2: Evidence for trade-offs between linguistic and phonetic processing. Journal of Speech and Hearing Research, 34, 879-892.

Raven,J.C. (1962). Ravens Coloured Progressive Matrices. London: Lewis \& Co. Ltd.

Rondal,J. (1994). Language Development in Adults with Down's Syndrome. Paper presented at International Conference on Language and Cognitive Development in Children and Adults with Down's Syndrome, Sarah Duffen Centre, University of Portsmouth, UK September 1994.

Rosin,M., Swift,E., Bless,D. and Vetter,D. (1988). Communication Profiles of Adolescents with Down Syndrome.Journal of Childhood Communication Disorders. 12, 49-64.

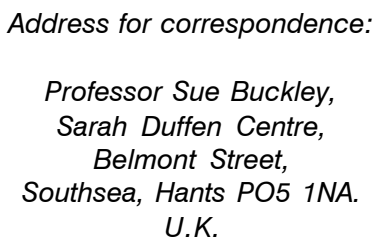

